\title{
O REGIONALNI GEOGRAFIJI NA LJUBLJANSKI UNIVERZI
}

\section{Mirko Pak*}

\section{IZVLEČEK}

UDK 913 (497.12)

Članek prinaša kritičen oris studijskih programov in studija regionalne geografije na ljubljanski univerzi, ter znanstveno-raziskovalnega dela na tem podroxju.

\section{ABSTRACT}

UDC 913 (497.12)

ABOUT REGIONAL GEOGRAPHY AT THE UNIVERSITY OF LJUBLJANA

The article presents critical description of studying programs and study of regional geography at the University of Ljubljana and of scientific research work in this domnion.

I.

Ob vseh dilemah in razpravah o predmetu, vsebini, teoriji, metodologiji in kvaliteti naše geografije, je bila večinoma $v$ ospredju tudi regionalna geografija kot najbolj kompleksna prostorska sinteza. K temu je navajala tradicija same stroke, najsirša splošno izobraževalna funkcija regionalne geografije, ter njena že kar dolgoletna kriza pri nas in v svetu. Od tod stevilne razprave o regionalni geografiji na sploh, ki so bile కe posebej živahne $v$ sedemdesetih letih, ob novih pogledih na regionalno geografijo kot vzgojno-izobraževalni predmet. Ker je bilo jedro regionalno geografskih prizadevanj vseskozi na Oddelku za geografijo Filozofske fakultete kot najvisji vzgojno-izobraževalni in znanstveno-raziskovalni ustanovi, se je njena vloga v družbi in znanosti vedno kazala ne samo v objavah, temvex tudi v samem Studiju regionalne geografije na univerzi: v njeni zastopanosti, usmerjenosti ali metodoloski zasnovanosti in kvaliteti. Ne nazadnje, se splošno stanje regionalne geografije in njen neposredni pomen $\mathbf{v}$ visokołolskem geografskem izobraževanju kaže v sami zainteresiranosti visokošolskih ucitcljev za regionalnogeografsko tematiko in v že velikokrat zapisani resnici, da po Meliku in Ilešiðu praktið̌no nismo veð imeli v regionalno geografijo močneje usmerjenih strokovnjakov. Vse bolj iluzorno je tudi razmišljanje o takozvanih regionalnih specialistih. Sicer so se obcasno pojavljale subjektivne sodbe o dobrih regionalnih geografih, ki pa žal s svojimi, na bolj ali manj tradicionalni metodologiji grajenimi regionalnogeografskimi prikazi posameznih pokrajin ali njihovih posameznih delov, niso vidneje prispevali $\mathrm{k}$ razvoju naše regionalne geografije kot znanstvene discipline. To še posebej drži ob vedno bolj aktualni tezi o metodologiji kot osnovi vsakršnemu znanstveno-raziskovalnemu delu.

* Dr., Univ. prof., Oddelek za geografijo, Filozofska fakulteta, 61000 Ljubljana, Aškeræ̌eva 12 , YU 
O nasi regionalni geografiji je bilo doslej že kar precej napisanega, posebej ob življenskih jubilejih obeh naših velikih regionalnih geografov Antona Melika (Ilesix, 1960; Kokole, 1966) in Svetozarja Ileši (Vrißer, 1985), v burnih razpravah pred leti v Geografskem obzorniku (Gams, 1974 in 1977; Medved, 1973; Ilesix, 1974) in v zadnjem Casu na posebej regionalni geografiji posvecenemu jugoslovanskemu znanstvenem simpoziju z znaxilnim naslovom "Teorija in metodologija regionalne geografije" (Dela-6, 1987), ki ga je fi-ipravila Katedra za regionalno geografijo Oddelka za geografijo simooziju z znaxilnim naslovom "Teorija in metodologi I. Gams V. Klemen $x i x$, M. Pak, M. Klemencic, J. Markovic in F. Lovrencak poleg ostalega kar ižrpno predstavili problematiko predmeta, metodologije, teorije, aplikacije in vloge regionalne geografije, pixli rezuitati tega pa se vidijo v nadaljnjih prizadevanjih na tem podroxju ter $v$ velikih težavah pri uresnixevanju ATLASA SRS in Monografije Slovenije. Tako referenti, kot stevilni, generacijsko pestri razpravljalci so si bili povsem edini o potrebnosti regionalne gcografije, kljub silovitemu poveCanju pretoka informacij in o potrebi po njeni modernizaciji. Ni pa bilo posebej tehtnih prispevkov o problematiki regionalizacije, kar je po IlesiŁu, ne glede na obટasno zanimanje nekaterih geografov ob prakticnih potrebah (Vrišer, Gams, Radinja), mox̌no nazadovalo.

II.

V študijskih programih Oddelka za geografijo so bili regionalnogeografski predmeti vedno ustrezno zastopani, delež njihovih ur predavanj, vaj in seminarjev pa se je gibal med 25 in $40 \%$. Potrebnost regionalne geografije torej nikoli ni bila sporna, o vsebini in metodologiji ter konceptu posameznih regionalnogeografskih predmetov pa so se zlasti v zadnjih petindvajsetih letih gledanja uxiteljev moxno razlikovala, od Mclikovega in IlesiŁevega koncepta, preko ‘olski praksi prilagojenega koncepta podajanja snovi, do problemskega prostopa. Vse to odseva iz preglednice petih primerov znaxilnih obdobij studija geografije, ki so rezultat reformnih prizadevanj in so se močno dotaknila tudi regionalnogeografskih predmetov (TABELA 1).

Zaradi pomanjkanja podatkov za predvojno obdobje o Studiju geografije, začenjamo prikaz s prvimi stirimi povojnimi leti od 1945 do 1949 , ko se je geografija predavala ciklieno.* V tem obdobju je bilo regionalni geografiji odmerjeno 28 ur predavanj. Ker so bili seminarji r'sebinsko združeni s splošnimi predmeti, ni razviden ccloten delež regionalne geografije. Nedvomno pa je bil, glede na skromno skupno stevilo ur, regionalni geografiji namenjen večji delež ur kot v kasnejših obdobjih. Znaxilna je skromna zastopanost geografije Slovenije in Jugoslavije, ter kar 10 ur geografije Evrope z dodatnimi stirimi urami Geografije SZ. Snov se je predavala po kontinenih.

* Vir: Geografski vestrik 1946, 1947, 1948-49, 1950 
TABELA 1::REGIONALNA GEOGRAFIJA V ŠTUDIJU GEOGRAFIJE NA LJUBLJANSKI UNIVERZI

Predmet

Študijsko obdobje/število ur
$\begin{gathered}1945-49 \\ \text { P }\end{gathered} \quad$ P V V S P V S P V V S P V S**

Geografija Slovenije

in Jugoslavije

Geografija Jugoslavije

$\begin{array}{lllll}12 & 7 & 7 & 9 & 1\end{array}$

Geografija Evrope

Geografija SZ

$2 \quad 3$

Gcografija Azije

Geografija Afrike

Gcografija Severne Amerike 2

Geografija Latinske Amerike 3

Geografija Slovenije

Geogr. proux. domačega kraja

Izbrana poglavja iz regionalne gcografije

Regionalna geografija sveta

Geografija tujih dežel

Scminar iz regionalne geografije

Regionalna geografija

Slovenije

Regiona!na geografija Jugoslavije

Regionalna geografija Evrope

Regionalna geografija sveta

Seminar iz reg. g. Slovenije

Seminar iz rcg. g. Jugoslavije

Seminar iz. reg. g. sveta

Seminar iz reg. g.

Slov., Jug. in sveta

Geografija Slovenije

Gcografija Jugoslavije

Geografija Evrope in SZ

Geografija Afrike in Azije

Geografija Angloamerike in Avstralije

Geografija Latinskc Amerike
2

42

2

7

$\begin{array}{ll}3 & 2\end{array}$

2

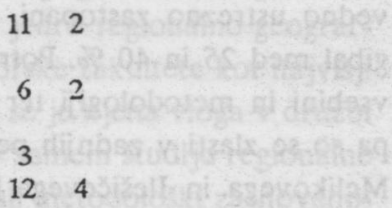

2

2

1

4

$\begin{array}{lll}50 & 10 & 30^{* * *}\end{array}$

$\begin{array}{lll}60 & 15 & 30\end{array}$

$\begin{array}{lll}45 & 5 & 10\end{array}$

$\begin{array}{lll}50 & 10 & 30\end{array}$

$\begin{array}{lll}30 & 15 & 30\end{array}$

$\begin{array}{lll}30 & 15 & 30\end{array}$

\section{SKUPAJ}

28

$\begin{array}{lllllll}23 & 7 & 7 & 25 & 7 & 2 & 32\end{array}$

$8 \quad 9265 \quad 70 \quad 160$

* Skupno tedensko število ur, preračunano na en semester.

** P-predavanja, V-vaje, S-seminar

*** Skupno కtevilo ur 
V studijskem letu 1956/57, je stevilo regionalni geografiji namenjenih ur ostalo približno enako, s tem, da je bilo ob 23 urah predavanj, še sedem ur vaj in seminarja.* Geografiji Jugoslavije je bilo namenjenih kar 12 ali vec kot polovica ur predavanj, ter vse ure seminarja in vaj, pri katerih je bila vexinoma obravana problematika Slovenije. Regionalni geografiji kontinentov je bilo namenjenih 7 ur, predavanja pa so bila $v$ enotnem kursu "Izbrana poglavja iz regionalne geografije". Predaval se je tudi predmet "Geografsko prouðevanje domaðega kraja", kar je bilo blizu današnji lokalni geografiji, oziroma uvajanje v znanstveno-raziskovalno delo. Predavanja in seminar so bili ciklicni za studente vseh stirih letnikov. Regionalna geografija je bila tudi predmet A diplomskega izpita. Celotno regionalno geografijo sta od leta 1945 naprej predavala profesorja Melik in Ilesix, ki sta za vse predmete izdala tudi ustrezne univerzitetne uxbenike.

V studijskem letu 1960/61, je prišlo do temeljite reforme visokosolskega studija z uvedbo stopenjskega in dvopredmetnega కtudija. ${ }^{* *} S$ tem se je regionalna geografija deliia na splosen kurz na prvi, ter na poglobljen, problemsko usmerjen kurz na drugi stopnji studija. Študiju regionalne geografije je takßna zasnova vse prej kot koristila. $\mathrm{Na}$ prvi stopnji je bilo II. Studijsko leto skoraj v celoti namenjeno regionalni geografiji, na drugi stopnji pa tretje leto. Razlike med regionalnogeografskimi predmeti prve in druge stopnje so bile tudi $v$ nazivih. Na prvi stopnji smo imeli Regionalno geografijo Slovenije itd, na drugi stopnji pa Geografijo Slovenije itd. Mocan poudarek je bil na seminarjih in na drugi stopnji so bila predavanja cikliðna. Diplomski izpit na prvi stopnji $\mathrm{z}$ imenom Regionalna geografija je vkljuðeval celotno regionalno geografijo. Regionalna geografija pa je bila poleg ostalega vkljucena tudi v diplomski izpit na drugi stopnji. Moxno se je poveðalo sttevilo predavateljev regionaine geografije, ki so jo na prvi stopnji predavali V. Klemencix, V. Leban, J. Medved, na drugi pa S. Ilešix, V. Klemenčič in prva leta š A. Melik.

Manjక̌e spremembe je ux̌ni načrt doživljal tudi v sedemdesetih letih, ko se je število ur regionalne geografije povečalo na 32 in še posebej v drugi polovici, ko je prišlo do precejక̌njih vsebinskih sprememb. Regionalnogeografski predmeti so se preimenovali v Geografski problemi Slovenije in slovenskih pokrajin, Geografski problemi Jugoslavije, Geografija dežel v razvoju, Geografija razvitih dežel. Podoben koncept in poimenovanje je bilo zastopano tudi $\mathrm{v}$ srednjesolskih programih. $\mathrm{V}$ tem obdobju, pa tja do novega, moxno reformiranega studijskega načrta v Studijskem letu 1983/84 so se že navedenim predavateljem regionalne geografije pridružili క̌e I. Gams, M. Jeršič, F. Lovrencak, M. Pak, D. Radinja in M. Žagar.

* Vir: Seznam predavanj za študijsko leto 1956/57, Lj., 1956

** Seznam predavanj za študijsko leto 1960/61, Lj., 1960 
Nov Studijski načrt je prinesel regionalnogeografskim predmetom $32,7 \%$ vseh ur geografskih predmetov in $29,5 \%$ ur predavanj.+ Obravnava se je zopet vrnila na kontinente, metodologija podajanja snovi pa je $\mathrm{v}$ glavnem problemska. Bistvena novost je zgradba celotnega Studija geografije, ko analitienim predmetom v prvem in drugem letniku sledijo sintetski regionalnogeografski predmeti v tretjem letniku s 345 urami in v Cetrtem s 150 . Regionalno geografijo predavajo I. Gams, M. Jeršx, M. Klemencix, V. Klemencix, F. Lovrencak, M. Pak, in D. Radinja.

Spreminjanje stevila ur regionalne geografije in njenih posameznih predmetov ter vsebina kolegijev in njihovi nazivi, nedvomno kažejo na velike dileme o smotrnosti taksnega ali drugaðnega studija regionalne geografije na univerzi, ki so se vedno bolj prenasale tudi $v$ problematiko vsebine regionalne geografije $v$ srednji, pa tudi osnovni కoli. Te dileme so se poglabljale, na splošno pa je vloga regionalne geografije v Studiju samem nazadovala. Gams sicer smatra, da bi bili absolventi geografije dobro podkovani v kompleksni geografiji, v kolikor so geografske panoge orientirane k regionalnemu konceptu. (Gams, 1987, s. 10) Sam pa bi postavljal bolj v ospredje zasnovo regionalnogeografskih predmetov. Nekdanja bogata bera univerzitetnih uxbenikev iz regionalne geografije A. Melika in S. Ilešica, ki jo je dopolnil š J. Medved, je povsem usahnila. Vse manj je tudi regionalnih studij Jugoslavije in drugih dežel, iz cesar je mogoxe sklepati, da so se ob splošni specializaciji tudi predavatelji regionalne geografije primarno usmerili $v$ druga geografska področja. To velja tudi za regionalno geografijo Slovenije. Verna podoba tega so tudi vedno redkejse seminarske in diplomske naloge. Regionalnogeografskih diplomskih nalog je bilo do leta 1980 povsom usahnila. Vse manj je tudi regionalnih studij $1981-89$ pa le se 6 ali $4,7 \%$.

Tchten del studija geografije se izvaja v obliki terenskih vaj in terenskega dela, za katerega smo si skupaj s slusatelji vedno močno prizadevali. Žal nam gospođarska gibanja vedno bolj $k r x_{i j o}$ daljß̌a in dražja potovanja, terenske vaje $v$ druge države pa so $\mathrm{z}$ izjemo zamejstva postale že prava redkost.

Splošna podoba regionalne geografije na drugih jugoslovanskih univerzah ni nix boljふa. Ponekod ji je sicer odmerjenih nekaj ve飞 ur, v zadnjih letih izdani univerzitetni učbeniki pa so praktixno moxno pomanjkljivo predelani in neposodobljeni ponatisi bolj ali manj tradicionalnih, deloma močno zastarelih ux̌benikov. Novi regionalnogeografski prikazi Jugoslavije, Evrope in drugih kontinentov pa so sila redki in vecinoma zgrajeni na tradicionalni metodologiji. 
III.

Ob zgornjih kritixnih razmišlanjih o visokosolskem కtudiju regionalne geografije pa je treba povedati, da je $\mathrm{z}$ ustanovitvijo Geografskega inštituta na univerzi leta 1919 rəgionalna geografija doživéla velik razmah, kar je podrobneje prikazano v publikaciji Dela కt.4 (Lovrenðak, 1987). Posebej zaslužna za to sta nała nedvomno daleđ najbolj plodna regionalna geografa profesorja Anton Melik in Svetozar Ilešic, s svojimi monografijami Slovenije, Jugoslavije in tujih dežel ter s Stevilnimi drugimi regionalnogeografskimi studijami. Melik je že pred vojno napisal Jugoslavijo $v$ dveh delih (1921 in 1923). Leta $1935 / 36$ pa je pri Slovenski matici izsla njegova prva splošna knjiga Slovenije, temeljno delo o slovenskem nacionalnem ozemlju, ki so ji po vojni sledile stiri obsežne regionalne monografije: Slovenski alpski svet (1954), Štajerska s Prekmurjem in Mežiško dolino (1957), Posavska Slovenija (1957), Slovensko Primorje (1960) in 1963 ponovno splosna geografija Slovenije v prenovljeni izdaji. Temeljna je bila tudi njegova Jugoslavija iz leta 1958 , tretja predelana in razsirjena izdaja. Po vojni se je Mcliku s svojimi regionalnogeografskimi monografijami pridružil Ilešix, katerega obsežno delo je najbolje označil Vriłer: "Velik smisel za regionalno geografijo, ki ga je Ilesið vseskczi kazal, se najbolje odraža v Gospodarski geografiji sveta in seriji regionalnih geografij Afrike, Azije, Avstralije in obeh Amerik, ki jih je večji del priobcil v 60 -ih letih in ki so bile v Sirsi javnosti dobro sprejete zaradi poljudnega načina podajanja, izvrstne dokumentacije, odlixnega stila, nazornosti in dobre metodiðne zasnove. Ponatisnili so jih vexkrat in tudi v srbohrvašini. Enake ocene so veljale za njegove కolske uðbenike o obði in regionalni geografiji, ki jih žal publikacije, kasncje nastale ob uvajanju usmerjenega izobraževanja, $v$ nobenem pogledu niso dosegle. $\mathrm{V}$ geografski metodiki, nazornosti, razumljivosti, jasnosti izražanja in nacinu pisanja, je bil Ilesix nedosegljiv mojster, in tako naj bodo njegove publikacije zgled, $\mathrm{h}$ kateremu se bomo zatekli v marsikateri dilemi, bodisi da bomo žcleli utrditi geografsko izrazoslovje aii imenoslovje, ali pa bomo želeli dobiti potrditev o metodixni razvrstitvi snovi ali interpretaciji geografskih zakonitosti in spoznanj." (Vrišer, 1985. s. 5)

Mislim, da temu ni kaj dodati, కe posebej sprið̌ dejstva, da vexina teh monografij క̌e vedno s pridom služi srednješolcem in drugim. Ob tem pa bi se kazalo spomniti tudi njegovega kratkega a jedrnatega in preglednega regionalnega orisa Slovenije "Slovenske pokrajine" v Geografskem obzorniku 1956 st.2. V tem Casu je Ilešic pripravil tudi Gospodarsko in politixno geografijo sveta, ki je dopolnjena in predelana izšla kar sedemkrat. Kasneje je napisal కe celo vrsto ucbenikov za posamezne razrede gimnazije. (Lovrencak, 1987, s. 57)

Ilesič je tudi zasnoval predvideno regionalnogeografsko monografijo Slovenije (Geografski vestnik 1981). Pri razglabljanju o njenem konceptu, so se v redakciji pojavljali celo glasovi o tem, da bi kazalo le posodobiti Melikovo Slovenijo ali vsaj uporabiti njen koncept. 
V povojnem obdobju so sodelavci oddelka za geografijo napisali Stevilne geografske monografije stevilnih slovenskih pojkrajin, bili pa so tudi mentorji vsem doktorskim disertacijam in magistrskim nalogam pri nas. Vexina med njimi se odlikuje po svoji temeljitosti, skrbno zbrani dokumentaciji in sodobni metodoloski zasnovi. (Vrišer, 1976 , s. 115) V njih je bil uveljavljen temeljni geografski aspekt problemsko opredeljene kompleksne regionalne obdelave $z$ oloceno osnovno problematiko obravnavane regije v ospredju, kot so: Gamsovo "Pohorsko Podravje" (1959), Kokoletova "Gospodarska geografija in geografija naselij na podroxju med Savo in Sotlo" (1956), V. Klemenčica "Pokrajina med Snežnikom in Slavnikom" (1959), Melikova "Bovec in Bovško" (1962), Medvedova "Mcžiska dolina zadnjih 100 let" (1963), Žagar jeva "Gospodarska geografija Kozjanskega in nje problemi" (1967), JerSiŁeva "Blejski kot" (1967), Pakova "Družbenogeografski razvoj Zgornjega Dravskega polja" (1969) in stevilne druge analize posameznih regij ali njihovih delov.

Ob vsesplosni specializaciji v geografiji je Ilesix nenehno opozarjal o nadaljevanju dela na modernih in problemsko usmerjenih regionalnih analizah posameznih slovenskih pokrajin. V ta namen je ob zborovanjih slovenskih geografov napisal vrsto kompleksnih regionalnogeografskih orisov obravnavanih obmoxij: Glavne geografske poteze in problemi Pomurja, Vloga Koroške regije v slovenskem prostoru (1970), Soteljsko-voglanjska regija (1974), Pomen kompleksnega regionalnega aspekta v sodobni gcografiji na primeru alpskih predelov Slocvenije (1978), Gorenjska in njene rcgionalne opredelitve in notranja regionalna razčlenitev (1981). Zborniki referatov $z$ zborovanj slovenskih geografov naj bi predstavljali regionalne sinteze, a so $\mathrm{v}$ glavnem ostaii na ravni analitičnih prispevkov posameznih pokrajinotvornih clementov. Enako velja za analizo slovenskega alpskega sveta v Geografici Iugos!avici 9 (1987).

V zadinjih ietih nedvomno beležimo določene premike v metodoloßki zasnovi nekaterih kompleksnih prostorskih analiz, zlasti izpod peres mlajsih avtorjev. M. Klemencix pa se zavzema za sistemski pristop $\mathrm{v}$ regionalni geografiji, ki sledi induktivni poti znanstvenega dela in ugotavlja notranje povezanosti med elementi, torej sisteme (M. Klemencic, 1987. s. 37). Temu je poskusil slediti v clanku Lakota po svetu (Geografski obzornik 1985, st. 3). Nova metodološka iskanja pa so tudi osnova novejšim srednješolskim učbenikom, Geografiji Slovenije, Jugoslavije ter razvitim in nerazvitim državam.

Regionalnogeografska prizadevanja je spremljala tudi problematika regionalizacije. Melikova regionalizacija Jugoslavije (1958) je se danes aktualna, Ilesiceve regionalizacije Stovenije in Jugoslavije ter njene teorije in metodologije veljajo v Jugoslaviji za vodilne. (Geografska regionalizacija Jugoslavije, Geografski vestnik 1961; Slovenske pokrajine-geografska regionalizacija Slovenije, Geografski vestnik 1972; Severovzhodna Slovenija in njena regionalna razčlenitev, Geografski vestnik 1968 in druge.) 
Ileši je skupaj z D. Radinjo pripravil geografsko regionalizacijo Slovenije tudi za Atlas SR Slovenije, medtem ko se je I. Vrišer ukvarjal z regionalizacijami za potrebe regionalnega planiranja. Tudi Gams se zadnja leta ukvarja z regionalizacijo Slovenije, ki jo je predstavil v srednjesolskem ucbeniku.

IV.

Vecina geografov si je edina, da je regionalna geografija se vedno ena bistvenih osnov in neobhodnih pogojev za eksistenco geografije. Tudi $\mathbf{v}$ praksi narasca potreba po njej, zlasti v izobraževanju in regionalnem planiranju (Pak 1987, s. 29). Taka pa je potrebna krepke idejne in metodixne prenove. Potrebna je izboljsav in izhajati mora iz regionalne danosti, ne pa iz problemov. (Vriser, 1979, s. 87).

Ni dvoma, da je metodoloßka posodobitev regionalne geografije nujna, oprta na tehnixne novosti v znanstveno-raziskovainem delu. Res pa je tudi, da so stevilne zahteve po regionalnogeografskih studijah tako razlix̌ne, da povsem enotnega koncepta za regionalne analize in za popularne prikaze ni mogoce uporabljati. Predvsem pa je potrebno veliko več zanimanja in ukvarjanja $z$ regionalno geografijo, kar velja tako za univerzitetne uxitelje kot za Šrš krog geografov. Monografija Slovenije, za njen splošni del so večno gradiva prispevali ucitelji oddelka, in vsi stirje regionalni prikazi, naj bi pokazali novo pot. Vsekakor pa so tudi na podroxju regionalne geografije Jugoslavije in tujih dežel potrebna večja prizadevanja. Rezultat tega bi nedvomno bila bolǰ̌a regionalna geografija na sploh, boljši srednješolski uŁbeniki, ustreznejše vrednotenje regionalne ter celotne geografije. 


\section{LITERATURA}

IleSix, S., 1960. Ob sedemdesetletnici profesorja Antona Melika. Geografski vestnik XXXII, Ljubljana, s. 3-9

Kokole, V., 1966, Anton Melik (1.I.1890 do 8.VI.1966)- in memoriam. Geografski vestnik XXXVIII, Ljubljana, s. 3-10.

Vriß̌er, I., 1985. Slovenski geografi ob smrti akademika profesorja dr. Svetozarja Ilesič. Geografski vestnik LVII, 1985, Ljubljana, s. 3-6

Gams, I., 1974. O konceptu geografije za 2. in 3. razred. Geografski obzornik XXI, st.2, L jubl jana, s. 7-10

Gams, I., 1977. O regionalni geografiji, vrh ali anahronizem metodixne geografije. Geografski obzornik XXIV, st. 1-2, Ljubljana, s. 41-45

Medved, J., 1973. O novi orientaciji geografije kot ux̌nega predmeta. Geografski obzornik XX, st. 1-2, L jubljana, s, 22-30

Gams, I., 1987. Regionalna geografija v sistemu geografske znanosti. Dela 4, Ljubljana, s. $1-13$

Lovrencak, F., 1987, Regionalna geografija v slovenski geografiji. Dela 4, Ljubljana, s. $52-65$

Vrišer, I., 1976. Uvod v geografijo. Ljubljana

Klemenčič, M., 1987, Sistemska teorija: pot k novi regionalni geografiji. Dela 4, Ljub2. ljana, s. $32-40$

Pak, M., 1987. O sodobni regionalni geografiji. Dela 4, Ljubljana, s. 23-31

Vrišer, I., Razmišl janja o geografiji. Geograrski vestnik LI, Ljubl jana, s. 83-96 


\section{ABOUT REGIONAL GEOGRAPHY AT THE UNIVERSITY OF LJUBLJANA}

General crisis of regional geography also influenced study of regional geography at the the university. The quantity of lectures remains nearly unchanged but it is the importance of the subject which declines. Profesors Anton Melik and Svetozar Ilesic have held lectures of regional geography since 1961 and have devoted themselves on the subject. They wrote a number of university text-books in this domain. With the reform of study in 1960/1961 and introducing of degree and problem regional geography on the second degree. With abolition of degree-study in 1963/64 main part of regional geography was transposed to the third and fourth year of study. It's because of lecturer's specilization that they put less attention on regional geography. J. Medved was the only one who wrote university text-books in that period.

There were similar trends whithin regional-geographic scientific research work. It was on the special Yugoslav symposium "The theory and metodology of regional geography" 1987 in Ljubljana (Dela 4) where we discussed this problem in detail. Limited number of regional geographic studies in general, their complete absence for the region of Yugoslavia and other countries and great difficulties we have with realization of two main projects of Slovene geography, ATLAS SR SLOVENIJE and MONOGRAFIJA SLOVENIJE were some of consequences of diagreable trends. 